\title{
Quantitative measuring and influencing mechanism of urban and rural land intensive use in China
}

\author{
LI Guangdong ${ }^{1,2}$, ${ }^{*}$ FANG Chuanglin ${ }^{1}$, PANG Bo ${ }^{1,2}$ \\ 1. Institute of Geographic Science and Natural Resources Research, CAS, Beijing 100101, China; \\ 2. University of Chinese Academy of Sciences, Beijing 100049, China
}

\begin{abstract}
Land use issue is an important constraining force to limit economic sustainable development of China. Urban and rural rapid expansion depletes valued land resources under the background of rapid urbanization. An extensive use pattern might cause a serious waste of land resources. The study on influencing mechanism of land intensive use (LIU) in China at the county level is a key tool for effective LIU practice and policy-making. This paper uses OLS model, Spatial Panel Lagged model and Spatial Panel Error model to quantitatively analyze the influencing mechanisms of five class factors and 17 variables supported by GIS (Geographic Information System) and MATLAB. And a comprehensive data set was developed including physical geography and socio-economic information of 2286 counties. Meanwhile, the spatiotemporal pattern of LIU has discussed by means of GIS. The results show that Spatial Panel Data models are slightly superior to OLS model in terms of significance and confidence level. Regression results of these models indicate that industrialization, urbanization, economic development level, location, transportation and policy have significant impact on LIU of counties. The variables of physical geography are less significant than socio-economic variables. An ignored variable of historical factor, however, became the best significant factor. In the future, the LIU at the county level should take advantage of the new situation by enhancing favorable factors and reducing disadvantageous ones, which can be acquired by improving the entire level and quality of industrialization and urbanization. We argued that an efficient and complete land market and operating system should be built to reflect market-oriented activities at the first place, then, differential LIU regulation policies and measurements should be optimized according to regional differences. In the meantime, we should pay close attention to the carrying capacity of local resources and environments when conducting LIU practices.
\end{abstract}

Keywords: land intensive use; national territory; quantitative measure; influencing mechanism; influencing factors; spatial econometrics models; GIS; county; China

Received: 2014-01-20 Accepted: 2014-02-20

Foundation: The National Science and Technology Support Planning, No.2012BAJ22B03

Author: Li Guangdong (1986-), PhD, specialized in land use and land cover change (LUCC), urban geography, and urban \& regional planning. E-mail: ligd.11b@igsnrr.ac.cn

"Corresponding author: Fang Chuanglin (1966-), Professor, E-mail: fangcl@igsnrr.ac.cn 


\section{Introduction}

With the wave of urbanization all over the world, the dramatic changes in land use driven by urbanization have happened or are happening in developed or developing countries. Human activities in urbanized areas have become a key driving factor in global land use and land cover changes (Seto, 2011). But along with the accumulation of wealth and increasing human demand, the problem of urbanized areas' aggressive expansion causes the shortage of land resources and a series of serious eco-environmental problems. At present, the space expansion shows the character of simply irrational expansion and sprawl. The data of China Township Statistics (from 2008 to 2012) report that the central area of designated towns have increased from $82,411 \mathrm{~km}^{2}$ to $98,909 \mathrm{~km}^{2}$ with annual growth rate of $4.67 \%$ during the period 2007-2011, which means the annual expansion of the towns central area equals to a county with a larger land area. Meanwhile, the land use per capita is not very intensive, for example, the central area per capita is more than $400 \mathrm{~m}^{2} /$ person. And China City Statistical Yearbooks (from 1985 to 2012) show that the urban built-up area has increased from 8842 $\mathrm{km}^{2}$ to $47,750 \mathrm{~km}^{2}$ and the urban built-up area per capita has increased from $46.26 \mathrm{~m}^{2}$ to about $104.22 \mathrm{~m}^{2}$ between 1984 and 2011 (USNBS, 1985-2012; RSNBS, 2008-2012). Therefore, it can be seen that changes in the scale and growth rate of construction land indicate that China's urban construction land use is significant non-intensive use. In recent years, a "population reducing but land area increasing" phenomenon appeared in rural settlement areas, which results in the coexistence of blind expansion and hollowed village (Liu, 2007; Li et al., 2010). More seriously, such unscrupulous expansion and non-intensive land use have threatened vulnerable eco-environmental condition and ecosystems. In some areas, for example, the eco-environmental destruction resulted from the expansion of production and living space has evolved to a great barrier to regional sustainable development.

Besides the rapid expansion of urban and rural settlements, other types of land use also have the same problem. For instance, driven by economic development, the industrial development zone in rapidly urbanized areas shows a disorderly arrangement, and the scattered pattern of industrial development still exists and has not been improved. A comprehensive upgrade with integration and optimization of industrial space is in urgent need. On the contrary, with more abandoned agricultural land and increasingly severe urban sprawl, high quality cultivated land decreases dramatically, which arises great social attention for food security. From an ecological point of view, plenty of wetlands, woodlands and natural water disappear because of rapid urbanization and human activities. If following this pattern, it can lead to a more unsustainable future for urban economic development. Meanwhile, the protection of eco-environment space is still a touchy issue.

In China, the new requirement for land intensive use was proposed in the Report of the 18th CPC (Communist Party of China) National Congress. It stated that "We should conserve resources and efficiently use them and bring about a fundamental change in the resource utilization pattern. We should strengthen conservation efforts, gradually reduce energy, water and land consumption per unit of GDP, and use such resources in a better and

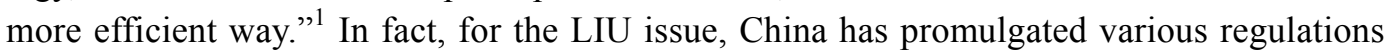
and decrees at the national level, including more than ten documents are closely related to

\footnotetext{
${ }^{1}$ Source: http://www.gov.cn/ldhd/2012-11/17/content_2268826.htm.
} 
land intensive use between 2004 and 2012, which stated the policy of land intensive use, the provisions of industrial land and rural residence land intensive use, and the construction of land intensive use institution. Among those documents, the Notice on Promoting the Land Economical and Intensive Utilization $(2008)^{2}$ issued by the State Council and the Decision of the CPC Central Committee on Major Issues Concerning Rural Reform and Development $(2008)^{3}$ announced by the Third Plenary Session of the 17 th CPC are programmatic files in intensive land utilization, in which the requirements of improving construction land efficiency and promoting highly efficient of land intensive use are clearly stated.

The pervious researches of LIU mainly focus on measuring the land intensive use level, exploring impact factors, describing the subsequent effects, and how to implement the land intensive use, etc. For evaluation of intensive land utilization degree, most of the researches focus on the intensive land use evaluation of construction land, development zone, rural land and urban land potential. And some national-level regulations have played an important role in land intensive use evaluation, such as The Economical and Intensive Use of Construction Land Evaluation Procedures (TD/T1018-2008), The Technical Procedures of Urban Land Intensive Utilization Potential Evaluation (Trial Edition), and The Evaluation Procedures of Development Zone Land Intensive Utilization (TD1029-2010). By constructing indicators system and developing fundamental evaluation method, a large number of scholars have conducted empirical studies, for example, Chen Yuqi et al. (2009) worked on the spatiotemporal change of cultivated land intensive degree, Huang Daquan et al. (2009) evaluated the intensive utilization level of industrial land, Wang Mei and others studied the intensive utilization degree for development zone (Wang and Qu, 2004; Shao and Wang, 2004). Later, some scholars pay attention to the regional differences (Feng et al., 2007) and potential estimation of intensive land use (Li et al., 2006; Xu et al., 2011). Meanwhile, the changes in industrial structure and industrial agglomeration, land use structure, price and efficiency, transportation infrastructure and eco-environment that triggered by land intensive use also drew many researchers' attention (Lin and Ben, 2009; Meng et al., 2008; Geurs and van Eck, 2003). In addition, many studies conclude that some specific measures, like planning, market adjusting, government regulating, and public participation are effective, for land intensive use. Generally, a complete framework of land intensive use research has been built up, and has played a significant role in socio-economic development.

The influencing factors and mechanisms analysis are always regarded as core issues for land intensive use, because they can contribute to understanding the causes, process and internal mechanism of LIU (Zhao et al., 2010). According to this, some exploratory researches have been carried out by scholars on this issue, which suggested that in China, many specific factors would affect the intensive land use, including land price and market mechanism (Yang et al., 2010), the total supply and scarcity degree of land, the level of economic development and industrialization, the land use structure and industrial structure (Yang et al., 2010; Chen, 2011), the population size and urbanization level (Yang et al., 2010), planning governance and macroeconomic policies (Wang and Ji, 2009), the land market and land trading system, the scientific and technological advancement (Wang and Ji, 2009), the land quality, location, traffic conditions and locational and eco-environmental conditions (Yang et

\footnotetext{
${ }^{2}$ Source: http://www.gov.cn/zwgk/2008-01/07/content_851750.htm.

${ }^{3}$ Source: http://www.gov.cn/jrzg/2008-10/19/content_1125094.htm.
} 
al., 2010).

Although the qualitative analysis of intensive land use factors basically clarified the possible causes of intensive land use, the quantitative studies are still rare. And most of the studies were observed at the provincial or regional level. To our knowledge, there is no related research on national LIU at the county level. So that the spatiotemporal pattern of intensive land use changes cannot be understood from the national perspective, and the size and magnitude of influencing factors cannot be depicted quantitatively. Therefore, it would be necessary to do a quantitative analysis at China's county level to explore the impact of specific factors and the mechanism, and to examine the credibility of qualitative analysis results. This paper is organized as follows. The next section presents a quantifying method for land intensive use. Section 3 introduces the influencing mechanisms model of LIU. Section 4 specifies the influencing mechanisms. Finally, the paper summarizes the major findings and policy implications.

\section{Quantifying land intensive use}

The comprehensive measuring method and data sources would be introduced in this section. To start with, some basic information and changes are described here, like administrative division, administrative division adjustments, and physical geographic and socio-economic data sources. As the fundamental statistics, physical geographic data was available through application and network data sharing. The traffic and transportation data have derived from transportation maps supported by the vectorization tool of ArcGIS10.1 ${ }^{\circledR}$. Socio-economic data of county level have acquired by on-line resources and statistical yearbooks. And other relevant data were obtained mainly from the Data Center for Resources and Environmental Sciences (Chinese Academy of Sciences, CAS), Data Sharing Infrastructure of Earth System Science of CAS, national statistical offices and network sharing.

\subsection{Data processing and adjustment of county administrative division}

In China, county administrative unit contains three categories, county (including autonomous county), county-level city, and municipal district. As the central part of China's county-level administrative unit, the history of county can be traced back to The Spring and Autumn Period and The Warring States Period, and it is really an extremely long-lived administrative unit, in spite of its changes in administrative areas, concepts and statements.

Frequent changing is a major feature of China's county-level administrative unit. For instance, in the early 1992, there were 2833 county-level administrative units in the Chinese mainland, including 1894 counties, 289 county-level cities and 650 municipal districts. And by the end of 2010, the total number of county-level administrative units in the Chinese mainland reached 2856, among which counties decreased to 633, county-level cities and municipal districts increased to 370 and 853, respectively. Although the number of county-level cities and municipal districts increased by 81 and 203 respectively, the number of counties reduced by 261 during the period of 1992-2010, which made the total number increase just by 23 . As a result, there is a need for taking administrative region adjustment. In this paper, in order to solve the problem of inconsistency of one region in different years and ensure the coherence in consecutive years, the backtracking method (tracking back from 
the final year to the starting year according to administrative division code) developed by $\mathrm{Hu}$ and Wei (2008), which is also of great benefit for satisfying the primary features of panel data and comparing between years. Thus, a number of 2286 stable county-level units were obtained between 1992 and 2010. Based on the National County-level Administrative Divisions Maps (1954-2010, SHP data) acquired from Data Sharing Infrastructure of Earth System Science of the Chinese Academy of Sciences, the final administrative divisions map has produced by ArcGIS10.1 ${ }^{\circledR}$. Figure 1 is a final map of the county-level administrative divisions (with the exception of Taiwan, Hong Kong, and Macao).

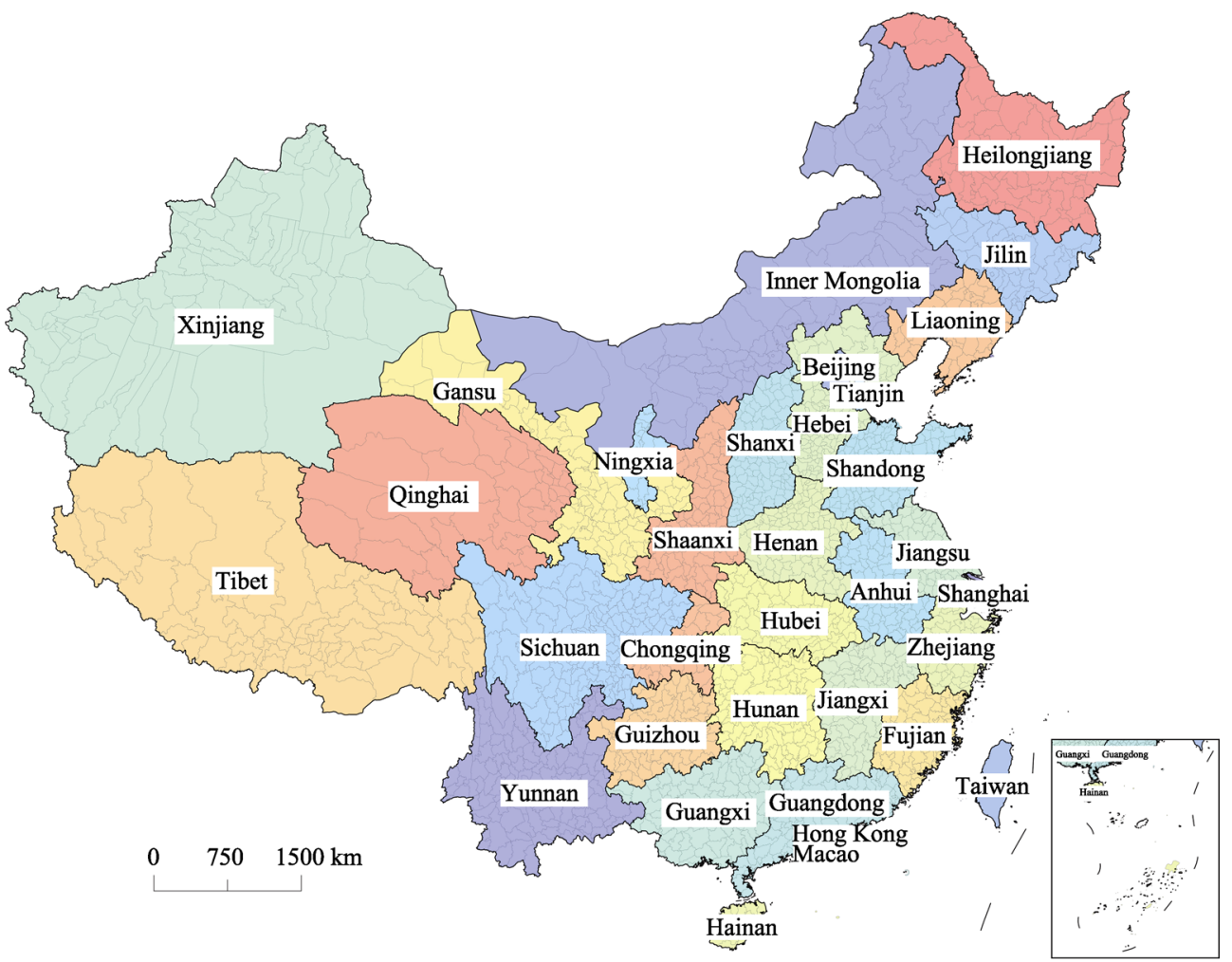

Figure 1 Administrative divisions of China at the county level

\subsection{Sources and processing method of natural geographic data}

Natural geographic data (raster data with $1 \mathrm{~km}^{2}$ resolution) have obtained from the Data Sharing Infrastructure of Earth System Science of CAS (www.geodata.cn) (Figure 2).

(1) The average elevation and slope data were extracted from Chinese National DEM with $1 \mathrm{~km}^{2}$ resolution, which came from the USGS. With ArcGIS10.1 ${ }^{\circledR}$ Spatial Analysis toolbox, the slope data are extracted based on DEM data.

(2) The average annual precipitation and temperature data were integrated on the basis of average data with $1 \mathrm{~km}^{2}$ resolution from 1970 to 2000 . The fundamental data came from Data Sharing Infrastructure of Earth System Science of CAS.

(3) The total amount of water utilization statistics was extracted from $1 \mathrm{~km}^{2}$ resolution grid data. The fundamental data was from Data Sharing Infrastructure of Earth System Sci- 
ence of CAS.

(4) The locational data, represented by the distance to the nearest coastal ports and the center of prefecture-level cities, were calculated by Network Analyst tool of ArcGIS ${ }^{\circledR}$ (Figure 3). The 47 coastal ports are identified by National Coastal Ports Arrangement Planning of China (2006), including 25 first-level ports and 22 second-level ports.

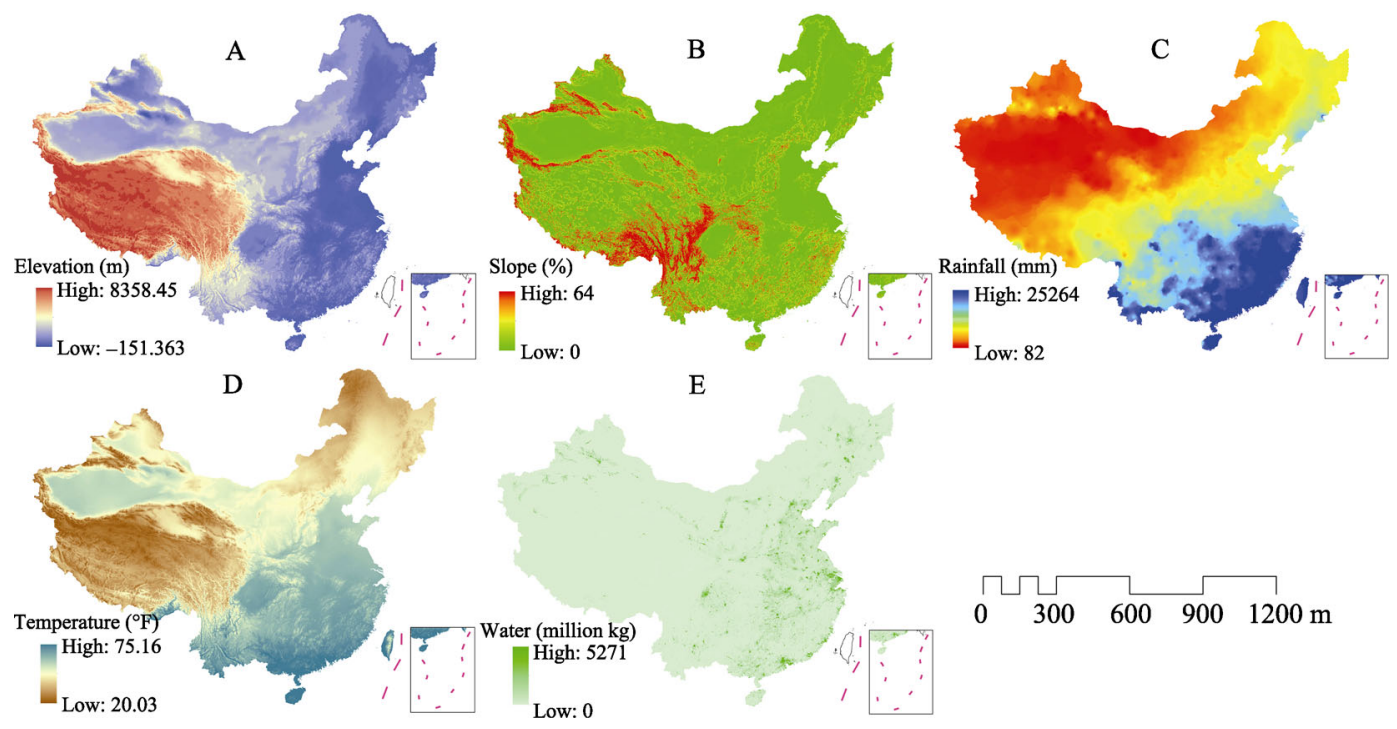

Figure 2 Maps of environmental factors of counties in China
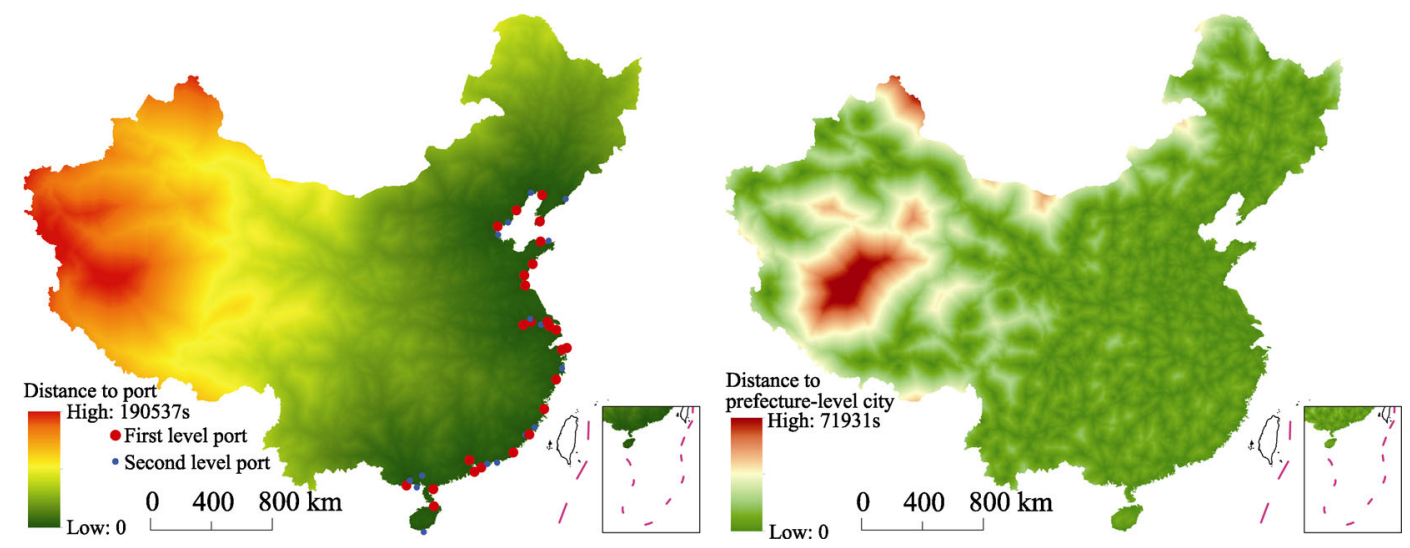

Figure 3 Maps of locational factors of counties in China

\subsection{Sources and processing method of socio-economic data}

The statistical data of counties (including autonomous counties) and county-level cities were mainly from China Statistical Yearbook for Regional Economy (2002-2011) and China County Statistical Yearbook (2000-2011). Meanwhile, the statistics of municipal districts were collected from China City Statistical Yearbook (1993-2011). And some missing data were completed through Statistical Yearbooks of relevant provinces (autonomous regions 
and centrally-administered municipalities) (1993-2011). On the basis of the panel data model's requirements and data availability, the socio-economic database of China at the county level (1992-2010) was finally built. The relatively complete data before 2000, however, just contained the data of the year 1992, 1995 and 1999 due to statistical deficiency.

For the traffic and transportation data, the year 2000 information was acquired from the Data Sharing Infrastructure of Earth System Science of CAS, and the information of 1992, 1995, 1999 and 2001-2010 were derived from the latest published transportation map using vectorization tool (Figure 4).

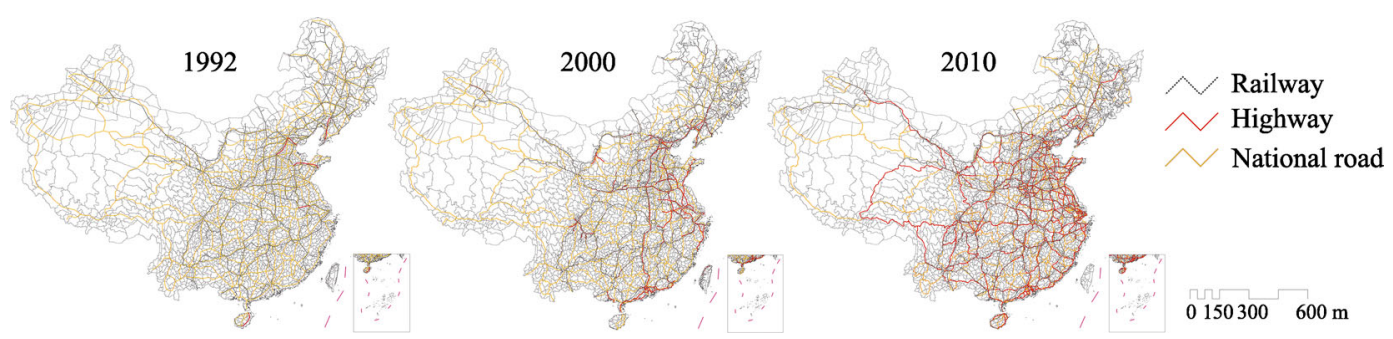

Figure 4 Spatial inequality of road network in China

As to the GDP data, since they are calculated in present value that cannot reflect price differences, a deflating processing would be necessary. Thus, the GDP data, deflated by each prefecture-level city's GDP index each year, were corrected to the initial level (1992). The urbanization level was represented by the proportion of non-agricultural population in the total population. The fixed asset investment of whole society was the substitute of fixed assets investment. The population density was calculated by the total population and land area (using ArcGIS ${ }^{\circledR}$ ). The industrialization level was expressed with the secondary industry output to GDP ratio.

The macroeconomic strategic policies were measured by preferential policies to different regions, provinces, cities and counties. Since the micro-level policy information were not available, this paper only examined three key national level policies including national strategies and macro-regional policies, state-level economic and technological development zone, and its status and importance in national strategy. And our quantitative preferential policy index was developed by referring to Demurger's methods (Demurger et al., 2002). Detailed information and setting refer to the study of Li and Fang (2013).

\subsection{Measuring model of land intensive use}

Regarded as one of the key issues in land science, land intensive use (LIU) measurement, especially the measuring model of LIU, has been studied by a large number of scholars. The existing researches show that single indicator measurement and comprehensive index measurement were generally used. From the perspective of national strategy, a complete evaluation index system of construction land intensive use has been built with two documents issued by Ministry of Land and Resources, namely, The Economical and Intensive Use of Construction Land Evaluation Procedures (published in November, 2008) and The Evaluation Procedures of Development Zone Land Intensive Utilization (published in April, 2010). However, it is a necessity to modify the existing index system due to data availability and 
differences of county-level LIU. Considering the nature of LIU, we suggested that the most important determinant factors of LIU are input per area, output per area and carrying capacity per area. Based on this judgment a three-dimensional LIU model was developed (Figure 5). Here, the land input is substituted by total fixed assets investment per area, the land output is represented by regional GDP per area, and the land carrying capacity is calculated by population density. The final LIU is determined by the integrated and comprehensive level of the input, output and carrying capacity. In this paper, the vector analysis of land utilization performance proposed by Ban et al. (2008) was used in the LIU evaluation at the county level. The LIU can be regarded as a vector $(\vec{A})$ that is a geometric sum of land input vector, land output vector and land carrying capacity vector $\left(\vec{A}_{x}, \vec{A}_{y}\right.$ and $\left.\vec{A}_{z}\right)$ in a three-dimensional Cartesian Coordinates System (Figure 6). According to vector algorithm,

$$
\vec{A}=\vec{A}_{x}+\vec{A}_{y}+\vec{A}_{z}
$$

the modulus of vector equal to

$$
|A|=\sqrt{A_{x}^{2}+A_{y}^{2}+A_{z}^{2}}
$$

where the modulus of vector represent LUI level of counties. Therefore, 3D model of county's LUI level can be defined as,

$$
F=\sqrt{f^{2}\left(A_{x}\right)+f^{2}\left(A_{y}\right)+f^{2}\left(A_{z}\right)}
$$

where $F$ is modulus of vector represents the length in three-dimensional space. $f\left(A_{x}\right), f\left(A_{y}\right)$ and $f\left(A_{z}\right)$ represent land input index, land output index and carrying capacity index, respectively.

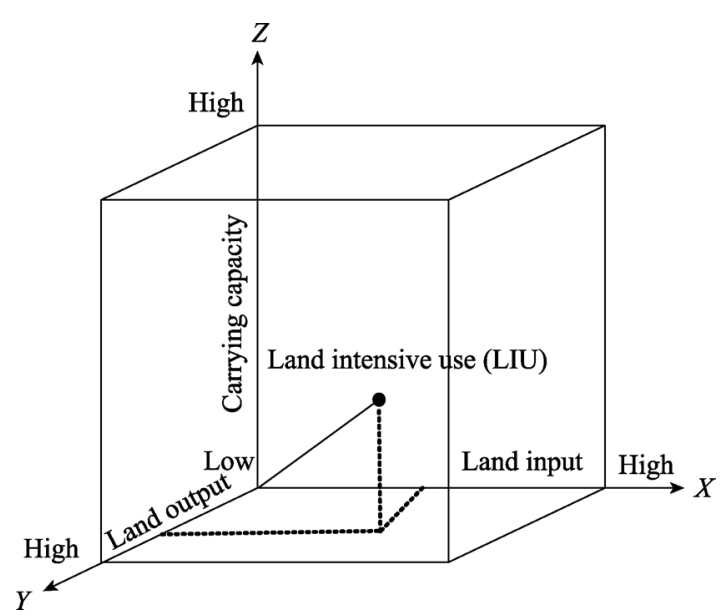

Figure 5 3D model of land intensive use

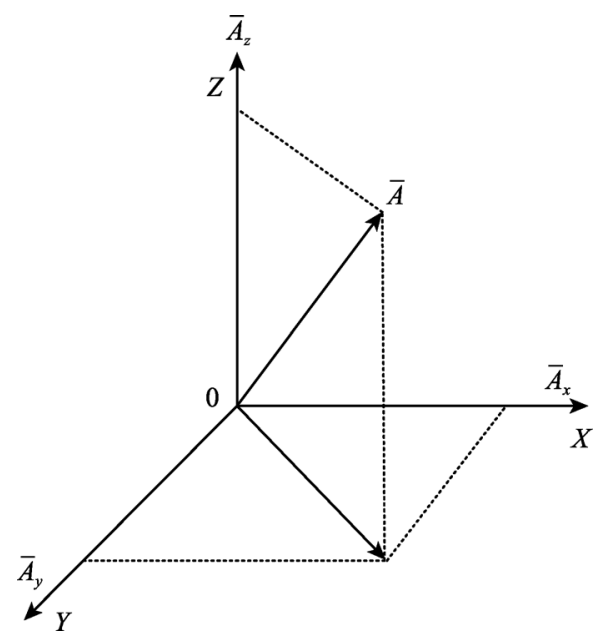

Figure 6 Vector analysis of land intensive use

With the aid of the abovementioned LIU model, 2286 counties' LIU was computed between 1992 and 2010, which was used as the dependent variable in influencing factor analysis of LIU. Figure 7 shows that the overall trend of LIU from 1992 to 2010 witnessed a gradual increase, during which time period a steady increase occurred from 1992 to 2000, a smooth and stable increase occurred between 2000 and 2003 (except a decline in 2001 and 2002), and a rapid development between 2003 and 2010 . 


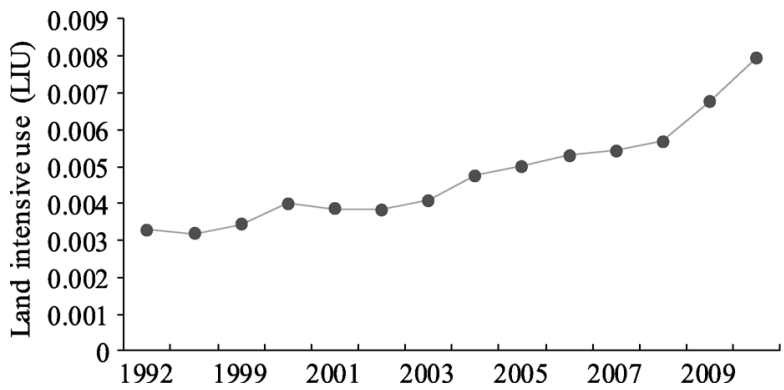

Figure 7 Temporal variation of land intensive use at the county level in China

Figure 8 shows that the regions of high LIU value concentrate in the right of $\mathrm{Hu}$ Line (Hehei-Tengchong Line), and the North China Plain region is also a high LIU value concentrated area. At the same time, five national-level urban agglomerations, namely the Beijing-Tianjin-Hebei urban agglomeration, the Yangtze River Delta urban agglomeration, the Pearl River Delta urban agglomeration, the Chengdu-Chongqing urban agglomeration, and the urban agglomeration around the Midstream of Yangtze River, are high LIU value concentrated areas either, which indicates that the LIU resulted urban agglomerations are much better than that in other areas. In the other regions, higher LIU value area shows a significant law of being distributed around capital cities. Besides, other higher LIU value areas include the mid-southern Liaoning urban agglomeration, the Lanzhou-Baiyin-Xining urban agglomeration, and the urban agglomeration of the West Coast of the Taiwan Strait.

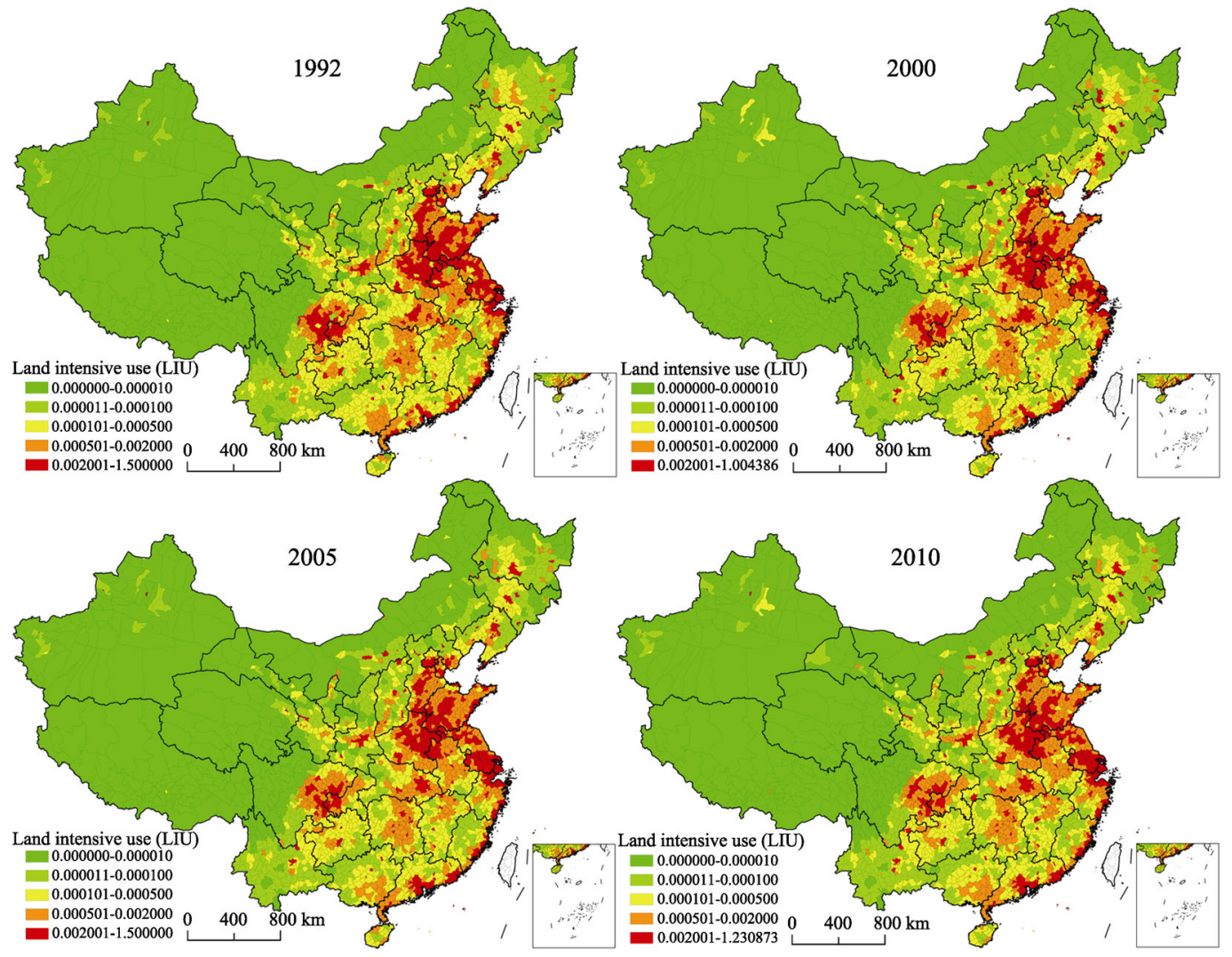

Figure 8 Spatial distribution of LIU at the county level in China 


\section{Influencing mechanisms model for land intensive use}

Based on the abovementioned analysis and existing research findings, the influencing factors of land intensive use at the county level can be categorized to two major types, one is time-varying factors that contain mainly socio-economic and transportation variables, and the other is the factors with spatial variations that include local natural environment and geographical location factors. For the time-varying factors, there are GDP per capita, industrialization level (proportion of secondary industry in the total GDP), urbanization level, annual population growth, and the density of road network. As to the space-varying factors, average elevation, average slope, average annual precipitation, annual average temperature, the distance to the nearest coastal ports, the distance to the nearest prefecture-level city centers, and regional dummy variables (East, Central and Western China were assigned value of 3,2 and 1 respectively ${ }^{4}$ ). In addition, some macro strategic policy factors were set to examine the effect of preferential policies on counties. And the detailed information can be provided in Table 1.

Table 1 Preliminary analysis of influencing factors for land intensive use at the county level

\begin{tabular}{|c|c|c|c|}
\hline Variable category & Variable name & Description & Impact \\
\hline Dependent variable & $L I U$ & Land intensive use level & \\
\hline \multirow{4}{*}{$\begin{array}{l}\text { Socio-economic } \\
\text { factors }\end{array}$} & $L N G D P$ & Constant GDP per capita & + \\
\hline & $\angle N P O P$ & Population growth & + \\
\hline & $I N D$ & Share of the output value of the secondary industry in GDP & + \\
\hline & $U R B A N$ & Share of non-agricultural population in total population & + \\
\hline \multirow{5}{*}{$\begin{array}{l}\text { Environmental } \\
\text { factors }\end{array}$} & $L N E L V$ & Average elevation & - \\
\hline & LNSLOPE & Average slope & - \\
\hline & LNRAI & Average rainfall & + \\
\hline & LNTEM & Average temperature & $?$ \\
\hline & LNWATER & Water resources utilization & + \\
\hline \multirow{6}{*}{$\begin{array}{l}\text { Transportation and } \\
\text { locational factors }\end{array}$} & LNDIST_PORT1 & Distance to the nearest first level ports & - \\
\hline & LNDIST_PORT2 & Distance to the nearest second level ports & - \\
\hline & LNDIST_CITY & Distance to the nearest prefecture-level cities & - \\
\hline & LNTRAN_DENS & Railway, highway and national road density & + \\
\hline & $R E G$ & Regional dummy variables & + \\
\hline & CITY_COUNTY & City and county dummy variable ( 1 or 0 ) & + \\
\hline \multirow{3}{*}{ Policy factors } & \multirow{3}{*}{ POLICY } & Strategic preferential policy & + \\
\hline & & State-level economic and technical development zones & + \\
\hline & & $\begin{array}{l}\text { Location in country's urban system and development orien- } \\
\text { tation for Development Priority Zones }\end{array}$ & + \\
\hline Historical factor & $L I U \_A 0$ & The base year is 1992 & + \\
\hline
\end{tabular}

${ }^{4}$ Eastern China includes 11 provincial level administrative units (Beijing, Tianjin, Hebei, Liaoning, Shanghai, Jiangsu, Zhejiang, Fujian, Shandong, Guangdong and Hainan); Central China includes 8 provincial level administrative units(Heilongjiang, Jilin, Shanxi, Henan, Anhui, Jiangxi, Hunan and Hubei); Western China includes 12 provincial level administrative units (Guangxi Zhuang Autonomous Region, Chongqing, Sichuan, Guizhou, Yunnan, Gansu, Shaanxi, Inner Mongolia Autonomous Region, Ningxia Hui Autonomous Region, Xinjiang Uygur Autonomous Region, Qinghai, and Tibet Autonomous Region). 
According to the preliminary analysis result of influencing factors, an econometric model was developed as follows:

$\mathrm{LIU}=f$ (Socio-economic factors, Environmental factors, Transportation and locational factors, Policy factor, Historical factor)

where the dependent variable is Land Intensive Use, and its time period is 1992-2010 (the data of 1993, 1994 and 1996-1998 are missing).

For a long time, OLS model is always recognized as the standard analytical framework in econometric analysis. However, such standard analytical framework probably neglects spatial dependence which could result in biased estimation and even invalidity of traditional OLS model. Hence, many studies attempt to eliminate this limitation. The spatial econometric model is a key effort. Spatial Econometrics developed from the groundbreaking work of Cliff and Ord (1972, 1981). Later, Anselin (1988) and Elhorst (2003) introduced spatial lagged error term into the traditional model, and Elhorst analyzed the estimation method of spatial data model systematically, which gradually brought such model to perfection (Elhorst, 2010). The most developed and commonly used approaches in spatial econometric analysis are spatial autoregressive model (SAR) and spatial error model (SEM). In the SAR model, the spatial influence and spillover effect of neighboring spatial units on target units are examined, and it allows the single regional observation $(i)$ of dependent variable relies on the adjacent regional observation $(j \neq i)$.

Therefore, the SAR model of county-level LIU influencing factors can be set like this,

$$
L I U=\alpha+\rho \sum_{j=1}^{N} w_{i j} L I U+\beta X_{i j}+\varepsilon_{i} \quad \varepsilon_{i} \sim \operatorname{Nid}\left(0, \sigma^{2}\right)
$$

where $\alpha$ is the intercept, $\rho$ is the spatial autocorrelation coefficient, $w_{i j}$ is the spatial weight matrix; $\varepsilon_{i, t}$ is the distributed error term; $\beta$ is the influencing coefficient; $X_{i j}$ is independent variables. The spatial weight matrix was calculated by Chinese County Map that contains the county centers' geodesic latitude and longitude coordinates, which was obtained from Data Sharing Infrastructure of Earth System Science of CAS. The extraction of geographic coordinate information was accomplished under the help of Arcgis10.1 ${ }^{\circledR}$, and the transformation of this information was achieved with Matlab 2012 $\mathrm{a}^{\circledR}$, specifically, with the xy 2 cont code $^{5}$, which generates to a $2286 \times 2286$ contiguous matrix.

When there is a spatial interaction in the error term or a space covariance between different regions, it needs the spatial error model to explain (Wang et al., 2012). Hence, the SEM model of county-level LIU influencing factors can be set like this,

$$
L I U=\alpha+\beta X_{i j}+\varepsilon_{i}, \varepsilon_{i}=\gamma \sum_{j=1}^{N} w_{i j} \varepsilon_{i}+\mu_{i}, \mu_{i} \sim \operatorname{Nid}\left(0, \sigma^{2}\right)
$$

where $\gamma$ is spatial error coefficient.

The most commonly used estimation method in spatial regression model is the Maximum Likelihood estimation (LM) that includes some frequently used statistic indicators like LMerr, LMla-g, Robust LMerr and Robust LMlag. In this paper, we use LM estimation method in Elhorst's studies (Elhorst, 2003, 2010) and the latest Matlab codes (SAR and

\footnotetext{
${ }^{5}$ Code source: http://www.spatial-econometrics.com/.
} 
SEM) of spatial econometric analysis on the website of Donald J. Lacombe ${ }^{6}$ and the LeSage's website?

\section{Influencing mechanisms of land intensive use}

Considering the possible error of traditional OLS regression due to the time-varying and space-varying variables, this paper selected SAR and SEM models for estimation. Meanwhile, the OLS regression results are showed for comparative analysis. The results indicate that there is no significant spatial autocorrelation in land intensive use at the county level. The spatial autocorrelation were controlled by SAR and SEM models. From the coefficients and significance, the calculated results were robust.

In the following part, the previous qualitative analysis of LIU influencing factors would be modified with the results of quantitative analysis (Table 2).

(1) Generally, the level of economic development has a significantly positive impact on improving the county's LIU, but not that much as expected, which can be found in Model (1), Model (2) and Model (4). By comparing these models, Model (2) (the SAR fixed spatial effect model) is a better choice. But in Model (2), the elastic coefficient of per capita GDP to county-level LIU is very weak, just 0.000453. Although the impact direction is the same with the previous estimation, the impact is less.

All of the three models demonstrated that the population growth did not affect county-level LIU significantly, which was not consistent with previous estimation. As a general logical reasoning, population growth would increase the pressure on the land. Under the condition of limited amount of land, however, the demand can be met by exploring the internal potential of LIU. But the facts of Chinese counties were not entirely like this, which suggests that population growth of county level had no substantive effect on LIU. Moreover, the population growth might exacerbate the problem of urban land waste and sprawl to some extent.

The level of industrialization has significantly positive impact on the county-level LIU, which is consistent with our expectation. The reason of this result could be the promotion of industrial structure and the progress of industrialization, which made the way of land use transfer from the primary industry to the secondary and tertiary industries. From an impact degree perspective, the result of industrialization level was obviously higher than that of economic development. In Model (2), when the industrialization level increased by $1 \%$, the county's LIU would increase by $0.2470 \%$.

The impact of urbanization level on the county's LIU was extremely significant and important. Superficially, it seems that this result contradicted with the result of population growth. But a careful analysis would tell that the core of urbanization is the population transition from agricultural to non-agricultural identity, but not the regional total population growth, which indicated that the level of urban land intensive use was obviously higher than that of the whole region. To some extent, urbanization level defines a proportional relationship between urban area and the region, thus, it represented the level of county LIU. In Model (2), the elastic coefficient of urbanization level to county LIU is 0.005983 , which

\footnotetext{
${ }^{6}$ http://co-mmunity.wvu.edu/ dj1041/matlab.html.

${ }^{7}$ http://www.spatial-econo-metrics.com/.
} 
Table 2 Quantitative analysis results of influencing factors for land intensive use at the county level

\begin{tabular}{|c|c|c|c|c|c|}
\hline & (1) & (2) & (3) & (4) & (5) \\
\hline & OLS & $\begin{array}{l}\text { SAR fixed space } \\
\text { and time period } \\
(\mathrm{ML})\end{array}$ & $\begin{array}{l}\text { SAR fixed time } \\
\text { period (ML) }\end{array}$ & $\begin{array}{c}\text { SEM fixed space } \\
\text { and time period } \\
(\mathrm{ML})\end{array}$ & $\begin{array}{l}\text { SEM fixed time } \\
\text { period (ML) }\end{array}$ \\
\hline$\alpha$ & $\begin{array}{c}-0.001493^{* * *} \\
(-2.6120)\end{array}$ & & & & \\
\hline$L N G D P$ & $\begin{array}{c}0.000138^{* * *} \\
(2.1139)\end{array}$ & $\begin{array}{c}0.000453^{* * *} \\
(7.5172)\end{array}$ & & $\begin{array}{c}0.000459^{* * *} \\
(7.5232)\end{array}$ & \\
\hline$\angle N P O P$ & $\begin{array}{c}-0.000148 \\
(-0.9617)\end{array}$ & $\begin{array}{c}-0.000179 \\
(-1.3779)\end{array}$ & & $\begin{array}{c}-0.000165 \\
(-1.2498)\end{array}$ & \\
\hline$I N D$ & $\begin{array}{c}0.001056^{* * *} \\
(3.2009)\end{array}$ & $\begin{array}{c}0.002470^{* * *} \\
(8.8279)\end{array}$ & & $\begin{array}{c}0.001763^{* * *} \\
(3.4884)\end{array}$ & \\
\hline$U R B A N$ & $\begin{array}{c}0.002233^{* * *} \\
(7.4161)\end{array}$ & $\begin{array}{c}0.005983^{* * *} \\
(3.5428)\end{array}$ & & $\begin{array}{c}0.002536^{* * *} \\
(9.3160)\end{array}$ & \\
\hline POLICY & $\begin{array}{c}0.000251^{* * *} \\
(8.5146)\end{array}$ & $\begin{array}{c}0.000551^{* * *} \\
(8.7210)\end{array}$ & & $\begin{array}{c}0.000561^{* * *} \\
(8.7705)\end{array}$ & \\
\hline$L N E L V$ & $\begin{array}{c}-0.000167^{* * *} \\
(-4.7297)\end{array}$ & & $\begin{array}{c}-0.000144^{* * *} \\
(-4.0509)\end{array}$ & & $\begin{array}{c}-0.000168^{* * *} \\
(-4.6797)\end{array}$ \\
\hline LNSLOPE & $\begin{array}{c}-0.000062^{* * *} \\
(-2.6428)\end{array}$ & & $\begin{array}{c}-0.000059^{* *} \\
(-2.5075)\end{array}$ & & $\begin{array}{c}-0.000063^{* * *} \\
(-2.6210)\end{array}$ \\
\hline LNRAI & $\begin{array}{c}0.000131 \\
(1.6255)\end{array}$ & & $\begin{array}{c}0.000127 \\
(1.4923)\end{array}$ & & $\begin{array}{c}0.000132 \\
(1.5947)\end{array}$ \\
\hline LNTEM & $\begin{array}{c}0.000056 \\
(1.5794)\end{array}$ & & $\begin{array}{c}0.000052^{* *} \\
(2.0475)\end{array}$ & & $\begin{array}{c}0.000056 \\
(1.5465)\end{array}$ \\
\hline LNWATER & $\begin{array}{c}0.000005^{* * *} \\
(5.9565)\end{array}$ & & $\begin{array}{c}0.000005^{* * *} \\
(16.2101)\end{array}$ & & $\begin{array}{c}0.000005^{* * *} \\
(15.2856)\end{array}$ \\
\hline LNDIST_PORT1 & $\begin{array}{c}-0.000101^{* *} \\
(-1.9987)\end{array}$ & & $\begin{array}{c}-0.000093^{* * *} \\
(-2.7832)\end{array}$ & & $\begin{array}{l}-0.000101^{*} \\
(-1.9835)\end{array}$ \\
\hline LNDIST_PORT2 & $\begin{array}{c}-0.000065^{* *} \\
(-1.5784)\end{array}$ & & $\begin{array}{c}-0.000060^{* * *} \\
(-2.1576)\end{array}$ & & $\begin{array}{l}-0.000065^{*} \\
(-1.5756)\end{array}$ \\
\hline LNDIST_CITY & $\begin{array}{c}-0.000106^{* * *} \\
(-1.7944)\end{array}$ & & $\begin{array}{c}-0.000095^{* *} \\
(-2.1448)\end{array}$ & & $\begin{array}{l}-0.000105^{*} \\
(-1.7667)\end{array}$ \\
\hline LNTRAN_DENS & $\begin{array}{c}0.000076^{* * *} \\
(4.1285)\end{array}$ & & $\begin{array}{c}0.000419^{* * *} \\
(6.5455)\end{array}$ & & $\begin{array}{c}0.000075^{* * *} \\
(4.1050)\end{array}$ \\
\hline$R E G$ & $\begin{array}{c}0.000171^{*} \\
(2.5522)\end{array}$ & & $\begin{array}{c}0.000156^{* * *} \\
(2.3459)\end{array}$ & & $\begin{array}{c}0.000172^{* *} \\
(2.5190)\end{array}$ \\
\hline CITY_COUNTY & $\begin{array}{c}0.000682^{* * *} \\
(5.5233)\end{array}$ & & $\begin{array}{c}0.000674^{* * *} \\
(5.4681)\end{array}$ & & $\begin{array}{c}0.000681^{* * *} \\
(5.4984)\end{array}$ \\
\hline$L I U \_A O$ & $\begin{array}{l}1.002834^{* * *} \\
(758.0175)\end{array}$ & $\begin{array}{c}0.760664^{* * *} \\
(191.7858) \\
0.006915^{* * *} \\
(5.7392)\end{array}$ & $\begin{array}{c}1.004324^{* * *} \\
(770.4556) \\
0.006917^{* * *} \\
(5.7393)\end{array}$ & $\begin{array}{l}0.760664^{* * *} \\
(191.7857)\end{array}$ & $\begin{array}{l}1.002239^{* * *} \\
(762.4691)\end{array}$ \\
\hline$\gamma$ & & & & $\begin{array}{c}0.021971^{* * *} \\
(15.1074)\end{array}$ & $\begin{array}{c}0.025973^{* * *} \\
(16.1554)\end{array}$ \\
\hline Rbar $^{2}$ & 0.9537 & 0.9584 & 0.9534 & 0.9584 & 0.9536 \\
\hline$\sigma^{2}$ & 0.0001 & 0.0001 & 0.0001 & 0.0001 & 0.0001 \\
\hline LM lag & $3736.5680^{* * *}$ & & & & \\
\hline LM err & $2200.3740^{* * *}$ & & & & \\
\hline R-LM lag & $1755.2066^{* * *}$ & & & & \\
\hline R-LM err & $219.0127^{* * *}$ & & & & \\
\hline Durbin-Watson & 2.0005 & & & & \\
\hline Log-likelihood & 96323 & 99113 & 96300 & 99114 & 96272 \\
\hline
\end{tabular}

$T$ values are in parentheses

$* * *$ significant at $1 \%$ confident level, ** significant at $5 \%$ confident level, $*$ significant at $1 \%$ confident level. 
means an increase of $1 \%$ in the level of urbanization can improve county LIU by $0.5983 \%$.

As previous expectation, macro strategic policy did have important effect on the county's LIU. OLS model, SAR model and SEM model all reveal this similar phenomenon. In SAR model and SEM model, the elastic coefficients mean that an increase of $1 \%$ in the level of preferential policy can improve county LIU by about $0.05 \%$. However, it can be found that, compared with other factors, the impact of macro strategic policy was stronger than that of economic development, but obviously lower than that of the industrialization and urbanization level.

(2) Commonly, the impact of environmental factors on the county-level LIU was significant, except some of them. From the overall effects, however, the influence of environmental factors was weaker than that of socio-economic factors.

The results of average elevation and average slope were in accordance with previous assumptions, which showed that topographical factors had a significant impact on county-level LIU. There is a general trend that the higher of the elevation and slope value, the lower of the county's LIU. For the difficulty of land use, the higher of the elevation and slope value the more difficult of the land intensive use.

All the three models showed no significant impact on LIU from precipitation and temperature. But a general tendency can be found that in the area with higher precipitation amount and temperature, the LIU value would be higher, and vice versa, which is consistent with China's entire environmental suitability.

Strictly speaking, the total amount of water utilization is one of the socio-economic factors, but due to the lack of relevant data at the county level, we use this as a substitution. Judging from the coefficient, this factor has a moderately significant (0.000005) impact on LIU at the county level. Since the matching of land and water resources is the foundation for agricultural production and urban industrial development, the adequacy of water resources can indicate the quality of the land to some extent. Once again, this result confirmed the influence of land quality on LIU.

(3) The result indicates that the relationships between the six transportation and locational factors and LIU are significant.

The locational factors contained three indicators, that is, the distance to the nearest first-level coastal ports, the distance to the second-level coastal ports and the distance to the nearest prefecture-level city's center. These variables are significant in all models, and their coefficients are negative (e.g. in Model (3), the coefficients of these three variables are $-0.000093,-0.000060$ and -0.000095 , respectively). This finding implies that advantageous locational condition would be good for land development. As a result, investment per land area to these areas would be more than that to other remote areas.

LNTRAN_DENS, reflecting transportation condition, is significant in explaining LIU, and its coefficient is positive in all regression models. This result implies that transportation infrastructure construction was the foundation of regional development. As an important driving force for the changes of land use, transportation system often in keeping with spatial structure of regional development.

Regional inequality resulted from the combined effects of multiple factors. This regional inequality also affects the spatial distribution of socio-economic phenomena. The econometric results demonstrated that regional inequality did significantly affect land intensive use. 
Since Eastern China has developed for a very long time, the investment per land area is higher than other regions. And there is big gap between economic development and land supply. Thus, the land intensive use level in Eastern China was higher than that of Central and Western China. At the same time, the differences in land supplies, land prices, land marketization levels and foreign investments were also major factors that caused LIU differences. Because the short of land supply, the higher land price and marketization level, and the greater foreign investment in Eastern China contributed to a higher value of LIU than that of Central and Western China.

In addition, the differences between city and general county cannot be neglected. From the above econometric results, it could be found that land intensive use was influenced by city and county dummy variable (the influencing coefficient is about 0.0006), which suggested that the LIU of cities was obviously higher than general counties. This partly came from the effect of administrative factors, and most likely from the results of urban industrial agglomeration and clustering of production factors.

(4) As a frequently neglected factor, historical foundation has an important effect on land intensive use in our econometric analysis. Although some socio-economic issues and national policies were crucial influencing factors, they could not play important roles without local and regional historical foundations. Hence, the effect of a long-time accumulation of local and regional comprehensive elements and self-organization on land intensive use should be paid more attention to.

\section{Discussion and conclusions}

\subsection{Conclusions}

(1) The significant spatiotemporal difference of LIU was found in China at the county level. By building a three-dimensional LIU model with land input, land output and land carrying capacity, the level of land intensive use can be measured. Generally, China's county-level LIU experienced a gradual increase process from 1992 to 2010, during which time period a steady increase occurred from 1992-2000, a smooth and stable increase was for 2000-2003, a rapid development happened in 2003-2010. As to the spatial distribution, the high LIU value regions concentrate in the right of Hu's line (Hehei-Tengchong Line) and the North China Plain region is also a high LIU value concentrated area. Meanwhile, five national-level urban agglomerations, namely the Beijing-Tianjin-Hebei urban agglomeration, the Yangtze River Delta urban agglomeration, the Pearl River Delta urban agglomeration, the Chengdu-Chongqing urban agglomeration, and the urban agglomeration around the Midstream of Yangtze River, are high LIU value concentrated areas either, which indicates that the LIU resulted urban agglomerations are much better than other regions. In the other regions, the higher LIU value area shows a significant law of being distributed around capital cities. Besides, other higher LIU value areas include the mid-southern Liaoning urban agglomeration, the Lanzhou-Baiyin-Xining urban agglomeration, and the urban agglomeration of the West Coast of the Taiwan Strait.

(2) The socio-economic factors had a significantly positive impact on improving the county's LIU, but not that much as expected. Instead of substantive effect on LIU, China's county population growth probably exacerbated the problem of urban land waste and sprawl 
to some extent. But when the industrialization level increased by $1 \%$, the county's LIU would increase by $0.2470 \%$. The impact of urbanization level on the county's LIU was extremely significant and important, which shows an increase of $0.5983 \%$ in LIU was caused by $1 \%$ increase in the level of urbanization. Although macro strategic policy had a significant effect on the county's LIU, when compared with other factors, its impact was stronger than that of economic development level and obviously lower than that of the industrialization and urbanization level.

(3) Most of environmental factors have a significant effect on the county-level LIU. From the overall effects, the influence of environmental factors was weaker than socio-economic factors. There is a tendency that the higher of the elevation and slope value, the lower of the county's land intensive use. But the precipitation and temperature had no significant impact on LIU.

(4) The transportation and locational factors show the relative higher significance, but the influencing degree was different. The nearer of the distance to the nearest coastal ports and the prefecture-level city's center, the higher of the LIU value, which implies that advantageous location would be good for land intensive use. As the foundation of regional development, transportation factors also had significant impact on improving land intensive use. And the regional differences between the three regions of China did affect LIU. Meanwhile, the discrepancy between cities and general counties cannot be neglected.

(5) As a frequently neglected factor, historical foundation indeed has an important effect on land intensive use. The effect of a long-time accumulation and self-organization was the basis of county-level LIU.

\subsection{Discussion}

(1) The essence of improving county-level LIU is to take advantage of the new situation by enhancing favorable factors and reducing disadvantageous ones. It can be acquired by improving the entire level and quality of industrialization and urbanization. In detail, an efficient and complete land market and operating system should be built to reflect market-oriented activities at the first place. Then, the differential LIU regulation policies and measurements should be optimized according to regional differences. In the meantime, environment and resources protection should be emphasized based on the carrying capacity of local resources and environments. For the advantageous county units, favorable locational and transportation conditions should be fully used to promote input and output per land area. For the counties with disadvantaged conditions, the focus should be put on the relationships between human needs and land utilization potential. The economical and intensive land use practice should be launched on the premise of satisfying basic human needs.

(2) This paper developed a quantitative measuring method of LIU and constructed an analysis framework for LIU influencing factors. Then, the spatial econometric method was used to examine and demonstrate specific influencing factors. Moreover, the data acquisition method of integrating locational and socio-economic factors based on GIS is worth a wide application. However, a further and profound exploration on the detailed influencing mechanisms should be taken in the future. The aforementioned analysis shows that it is very important for enhancing the comprehensiveness of land use science by introducing econometric approach into land use science. 


\section{References}

Anselin L, 1988. Spatial Economy: Methods and Models. Dordrecht: Kluwer Academic Publisher.

Ban Maosheng, Fang Chuanglin, Liu Xiaoli et al., 2008. Comprehensive evaluation of land use performance of Beijing High-tech Industrial Zone. Acta Geographica Sinica, 63(2): 175-184. (in Chinese)

Chen Haiyan, 2011. Study on mechanism of land intensive use based on economic development pattern transformation: A case of Kunshan county in Jiangsu Province. Nanjing: Nanjing Agricultural University. (in Chinese)

Chen Yuqi, Li Xiubin, Tian Yujun et al., 2009. Structural change of agricultural land use intensity and its regional disparity in China. Journal of Geographical Sciences, 19(5): 545-556.

Cliff A, Ord J K, 1972. Testing for spatial autocorrelation among regression residuals. Geographical Analysis, (4): 267-284.

Cliff A, Ord J K, 1981. Spatial Processes: Models and Applications. London: Pion.

Demurger S, Sachs J D, Woo W T et al., 2002. The relative contributions of location and preferential policies in China's regional development: Being in the right place and having the right incentives. China Economic Review, 13(4): 444-465.

Elhorst J P, 2010. Spatial panel data models. In: Handbook of Applied Spatial Analysis. Berlin and Heidelberg: Springer, 377-407.

Elhorst J P, 2003. Specification and estimation of spatial panel data models. International Regional Science Review, 26(3): 244-268.

Geurs K T, van Eck J R R, 2003. Evaluation of accessibility impacts of land-use scenarios: The implications of job competition, land-use, and infrastructure developments for the Netherlands. Environment and Planning B: Planning \& Design, 30(1): 69-87.

Hu Angang, Wei Xing, 2008. Local disequilibrium of regional economic development: 1993 to 2005. Reform, (11): 68-76. (in Chinese)

Huang Daquan, Hong Lixuan, Liang Jinshe, 2009. Analysis and evaluation of industrial land efficiency and intensive use in Fujian Province. Acta Geographica Sinica, 64(4): 479-486. (in Chinese)

Li Guangdong, Fang Chuanglin, 2014. Analyzing the multi-mechanism of regional inequality in China. Annals of Regional Science, doi: 10.1007/s00168-013-0580-2.

Li Jinggang, Ou Minghao, Liu Zhijian et al., 2006. Research on the potential of land consolidation of development zones in Jiangsu Province. China Population, Resources and Environment, 16(6): 129-134. (in Chinese)

Li Yurui, Liu Yansui, Long Hualou, 2010. Spatio-temporal analysis of population and residential land change in rural China. Journal of Natural Resources, 25(10): 1629-1638. (in Chinese)

Lin S W, Ben T M, 2009. Impact of government and industrial agglomeration on industrial land prices: A Taiwanese case study. Habitat International, 33(4): 412-418.

Liu Yansui, 2007. Rural transformation development and new countryside construction in eastern coastal area of China. Acta Geographica Sinica, 62(6): 563-570. (in Chinese)

Meng Y, Zhang F R, An P L et al., 2008. Industrial land-use efficiency and planning in Shunyi, Beijing. Landscape and Urban Planning, 85(1): 40-48.

Rural Secretary of National Bureau of Statistics of China (RSNBS), 2008-2012. China Yearbook of Town Survey. Beijing: China Statistics Press. (in Chinese)

Seto K C, Fragkias M, Guneralp B et al., 2011. A meta-analysis of global urban land expansion. Plos One, 6(8): e23777.

Shao Xiaomei, Wang Jing, 2008. Appraisal of intensive land use of development zones in small towns: A case study of Cixi in Zhejiang Province. Progress in Geography, 27(1): 75-81. (in Chinese)

Urban Secretary of National Bureau of Statistics of China (USNBS), 1985-2012. China City Statistical Yearbook. Beijing: China Statistics Press. (in Chinese)

Wang Jiating, Ji Kaiwen, 2009. An empirical research on the factors influencing urban land intensive use: Based on the data of 34 sample cities in China. Economic Geography, 29(7): 1172-1176, 1181. (in Chinese)

Wang Jinfeng, Fischer M M, Liu Tiejun, 2012. Spatial Analysis of Economic and Social Science. Beijing, Science Press. (in Chinese)

Wang Mei, Qu Futian, 2004. Indicator system for land use intensity assessment of industrial enterprises in Kunshan Development Zone. China Land Science, 18(6): 22-27. (in Chinese)

Xu Y, Tang Q, Fan J et al., 2011. Assessing construction land potential and its spatial pattern in China. Landscape and Urban Planning, 103(2): 207-216.

Yang Feng, Yuan Chun, Zhou Wei et al., 2010. Study on the influencing factors to regional land intensive use. Resources \& Industries, 12(4): 67-73. (in Chinese)

Zhao Xiaofeng, Huang Xianjin, Chen Yi et al., 2010. Research progress in urban land intensive use. Journal of Natural Resources, 25(11): 1979-1996. (in Chinese) 